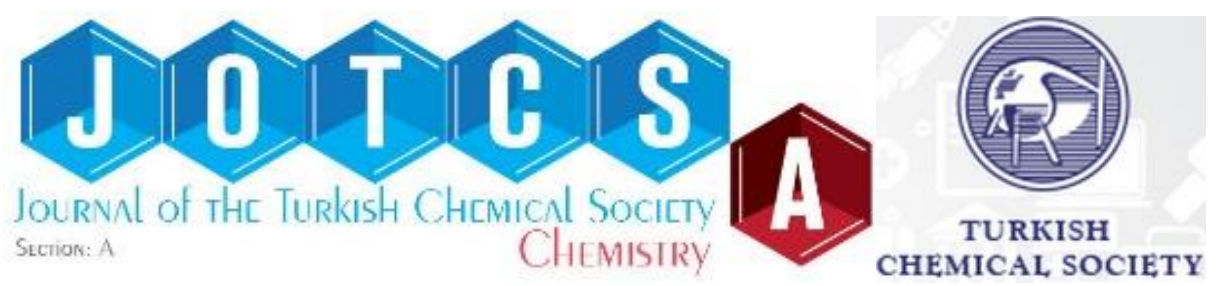

\title{
Compounds derived from flavonoids for photovoltaic applications. Computational chemical investigations
}

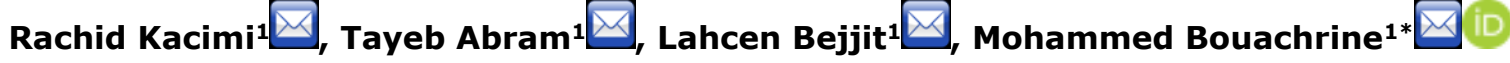 \\ 1 MEM, EST Meknes, University Moulay Ismail, Morocco.
}

\begin{abstract}
In this paper, we present a quantum chemical analysis of geometries and optoelectronic properties of a series of flavonoids and derivatives with the aim to research new molecules for applications in the fields of chemical physics and materials science. The calculations are based on the functional density theory (DFT) level of the B3LYP with 6-31G $(d, p)$. This method was used to calculate the energy of HOMO and LUMO level, the Egap (gap energy), the Voc open circuit voltage). The DFT (TD-B3LYP /6-31G (d, p)) was used to calculate ( $\lambda$ max maximum of absorption) as well as other quantum parameters. The study of organic solar cells cannot be effective unless accompanied by a thorough understanding electronic distribution on the HOMO and LUMO energy levels of the components, so the researchers calculated and discussed the HOMO, LUMO, energy gap, and Voc of the test compounds. The result shows that these studied molecules are good candidates for application in the fields of optoelectronic devices such as OLED, conducting devices and organic solar cells.
\end{abstract}

Keywords: Flavonoids, DFT, gap energy, optoelectronic devices. $V_{\text {oc }}$ (open circuit voltage). $\lambda_{\max }$ (wavelength ). OS(oscillator strengths).

Submitted: May 02, 2018. Accepted: August 30, 2018.

Cite this: Kacimi R, Abram T, Bejjit R, Bouachrine M. Compounds derived from flavonoids for photovoltaic applications. Computational chemical investigations. JOTCSA. 2018;5(3):1009-20.

DOI: http://dx.doi.org/10.18596/jotcsa.420458.

${ }^{*}$ Corresponding Author. E-mail: m.bouachrine@est-umi.ac.ma. Tel: +212660736921

\section{INTRODUCTION}

Flavonoids are derivatives of phenylobenzo-ypyrone and are frequently found in plants. They are natural pigments distributed throughout the plant kingdom where they function as UV filters and as a protective agent against pathogenic organisms (1). These compounds can be found in black tea and red wine, they are made in the body by the consumption of fruits, vegetables and cereals (2). Flavonoids are increasingly marketed for a variety of pharmaceutical, cosmetic and food products. The flavonoids have a common biosynthetic origin therefore have the same basic structural unit and fifteen carbon atoms consisting of two $\mathrm{C} 6$ rings ( $\mathrm{A}$ and $\mathrm{B}$ ) linked by a C3 chain (2-phenyl-1-benzopyran ring) (3). The effect of flavonoids in plants is partly due to their filter effect and their high absorption in the UV region of the spectrum (4). The flavonoids, according to their structure, have absorption maxima in the zone of 270 to $350 \mathrm{~nm}$ (5). Indeed, several patents and publications have claimed the analysis of flavonoids method microemulsion electrokinetic chromatography approach coupled with light-emitting-diode-induced fluorescence (LED-IF, $480 \mathrm{~nm}$ ) detection. The results obtained by this method show that most flavonoids were completely separated within $5 \mathrm{~min}$ without derivatization (6).

We exhibit here a complete computational investigation using the method functional density theory (DFT) and employing the B3LYP (Becke three-parameter Lee-Yang-Parr) exchange correlation functional with $6-31 \mathrm{G}(\mathrm{d}, \mathrm{p})$ in order to predict a qualitative description of the 
interaction. Firstly, we start by optimizing the studied structures; then from the most stable optimized structure, we determine the energy HOMO, LUMO and gap energy ( $\left.E_{\text {gap }}\right)$. This energy allows us to estimate and calculate the photovoltaic parameters. Extensive TimeDependent Density Functional Theory (TD-DFT) calculations have been carried out in order to obtain the maximum absorption wavelength. The<smiles>O=c1c(O)c(-c2ccc(O)c(O)c2)oc2cc(O)cc(O)c12</smiles>

M1: Kaempferol<smiles>O=c1c(O)c(-c2cccc(O)c2O)oc2cc(O)c(O)cc12</smiles>

M3 :Quercetin<smiles>O=c1c(O)c(-c2ccc(O)c(O)c2O)oc2cc(O)ccc12</smiles>

M5 : Fisetin structures of the studied molecules are shown in Figure 1, we will perform quantitative calculations on of the studied compounds and we will determine their optoelectronic, absorption and photovoltaic properties, the results obtained show that these materials have been proposed as good candidates in the fields of optoelectronic devices such as OLED, conducting devices and organic solar cells.<smiles>O=c1c(O)c(-c2ccccc2)oc2cc(O)ccc12</smiles>

M2 :Galangin<smiles>O=c1c(O)c(-c2cc(O)c(O)c(O)c2)oc2cc(O)ccc12</smiles>

M4 : Robinetin<smiles>COc1ccc(-c2oc3cc(O)cc(O)c3c(=O)c2O)cc1</smiles>

M6 : Kaempferide 
Kacimi et al. JOTCSA. 2018; 5(3): 1009-1020.<smiles>Cc1ccc2c(=O)c(O)c(-c3ccccc3)oc2c1</smiles>

M7 : 3-Hydroxy- flavone<smiles>O=c1c(O)c(-c2ccc(O)c(O)c2)oc2cc(O)cc(O)c12</smiles>

M9 : Morin<smiles>O=c1cc(-c2ccccc2)oc2ccccc12</smiles>

M11: 5-Hydroxy- flavone<smiles>[O]c1ccc2c(=O)cc(-c3ccccc3)oc2c1</smiles>

M13 : 8-Methoxy- flavone<smiles>O=c1c(O)c(-c2cc(O)c(O)c(O)c2)oc2cc(O)cc(O)c12</smiles>

M8 : Myricetin<smiles>O=c1cc(-c2ccccc2)oc2ccccc12</smiles>

M10 : Flavone<smiles>O=c1cc(-c2ccccc2)oc2ccc(O)cc12</smiles>
M12 :7-Hydroxy -flavone

Figure 1: The chemical structure of the studied compounds Mi. 


\section{MATERIALS AND METHODS}

The ground-state geometries of the studied molecules were optimized using DFT (Density Functional Theory) and employing the B3LYP method with $6-31 G(d, p)$ basis set for all molecules (7). In order to obtain the loaded structures, optimized structures of the neutral form are used. The calculations were carried out using the GAUSSIAN 9.0 program (8). The geometric structures of the neutral molecules have been optimized without constraint. We also reviewed the HOMO and LUMO levels; the $E_{\text {gap }}$ energy is evaluated as the difference between the HOMO and the LUMO, energies oscillator forces were studied using TD/DFT calculations of these optimized geometries. The energy of highest occupied molecular orbital (HOMO) and lowest unoccupied molecular orbital (LUMO) levels were examined and visualized using Gaussview 5 Program. In fact, these methods of calculation have been successfully applied to other conjugated polymers (9).

\section{RESULTS AND DISCUSSION}

The results of different optimizations to find the most stable structure for each studied molecule are presented in Figure 2. We found that the obtained structures have similar quasi-planar conformations.

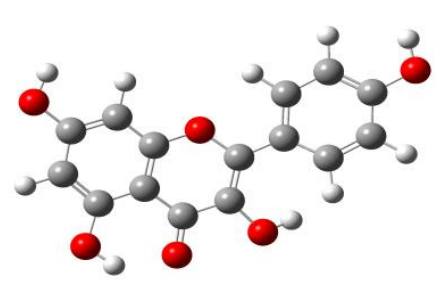

M1

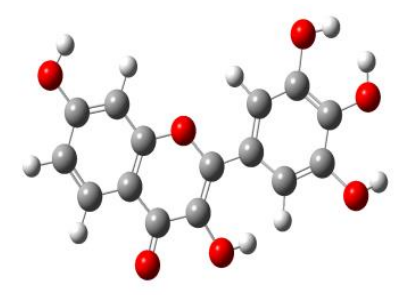

M4

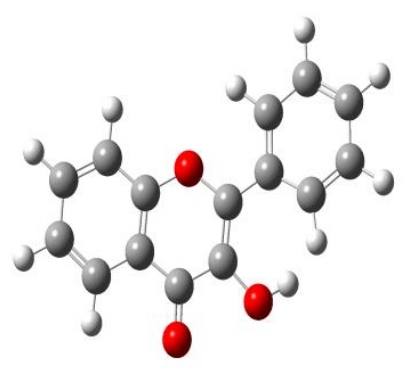

M7

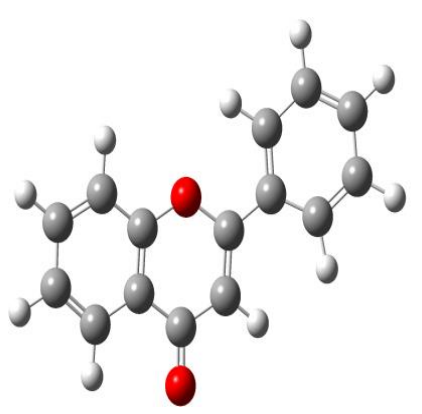

M10

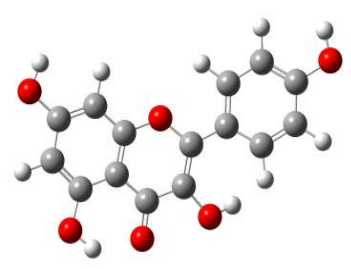

M2

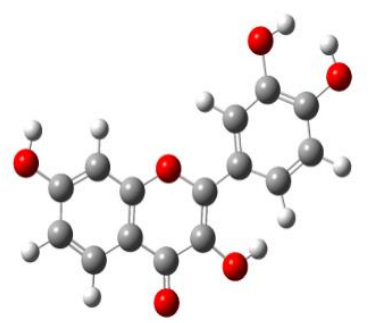

M5

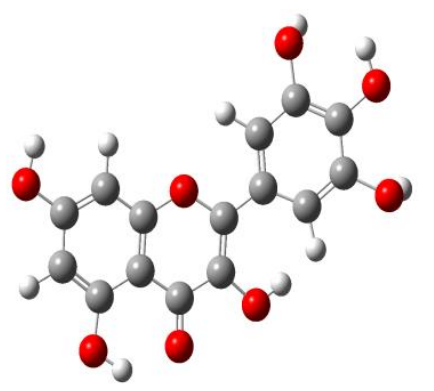

M8

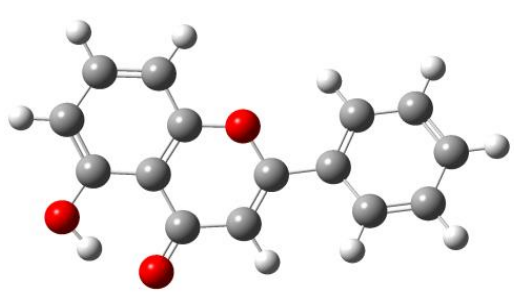

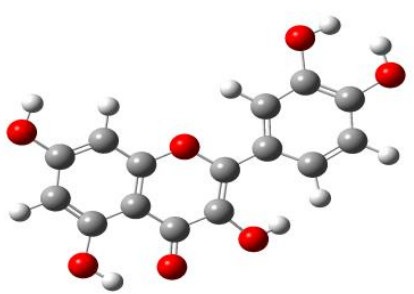

M3

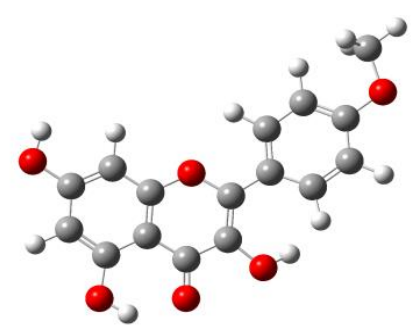

M6

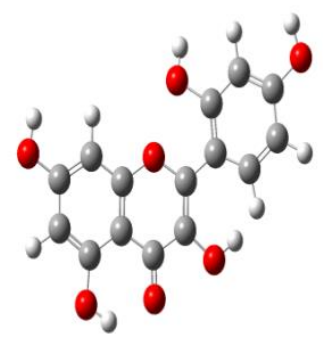

M9

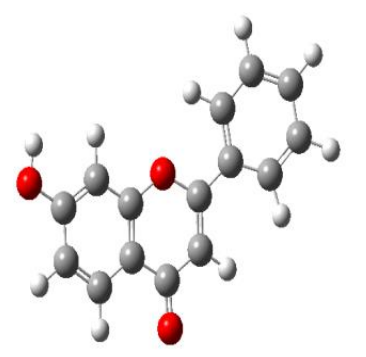




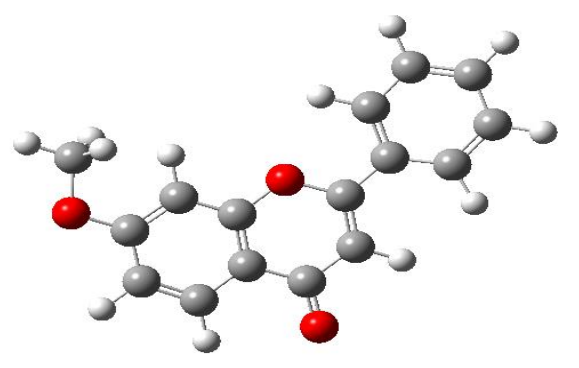

M13

Figure 2: Optimized geometries obtained by B3LYP / 6-31G (d,p) of the studied molecules.

From these optimized structures, we have determined the energies HOMO and LUMO in order to calculate the energy gap $\mathrm{E}_{\text {gap }}\left(\mathrm{E}_{\text {номо- }}\right.$ ELUMO). The energies of the HOMO and the LUMO levels of these compounds have been compared to those of the PCBM C60 to estimate the effectiveness in a donor-acceptor organic solar cells structure where the donor is the studied molecules and the acceptor is the PCBMC $_{60}(10)$.

$$
\eta=F F \frac{V_{o c} J_{s c}}{P_{i n c}}
$$

Where Jsc is the short-circuit current, and FF is the fill factor. For solar cells in the $(\mathrm{BHJ})$, the
Efficiency of the studied compounds suggested for photovoltaic devices can be estimated by calculation of the power conversion efficiency (PCE) which measures the amount of energy produced by a solar cell in relation to the power available in incident solar radiation $\left(P_{\text {in }}\right)$. Photovoltaic efficiency of the photovoltaic cell (power conversion efficiency) can be calculated using the following equation:

maximum open circuit voltage $\left(\mathrm{V}_{\mathrm{oc}}\right)$ can be expressed according to Eq. 2 (11).

$$
\left.\left.V_{\text {oc }}=\mid E_{\text {Номо }} \text { (Donor) }\right)|-| E_{\text {LUMO }} \text { (Acceptor) }\right) \mid-0.3
$$

We have also calculated for each couple (Donor / acceptor), the parameter alpha:

$$
\alpha_{\mathrm{i}}=\mathrm{E}_{\mathrm{LUMO}}(D \text { onor })-\mathrm{E}_{\mathrm{LUMO}}(A \text { cceptor })
$$

The above analysis shows that the LUMO levels of the compounds Mi are higher than the conducting band of PCBM (-3.7 eV). In addition, to efficiently inject the electron in the CB PCBMC60; the value of LUMO donor must be greater than that of PCBMC60. These driving forces are large enough for an efficient injection of electrons, since in organic solar cells the open circuit voltage depends linearly on the HOMO level of the donor and the LUMO level of the acceptor. The maximum open circuit voltage $\mathrm{V}_{\mathrm{oc}}$ of the solar cell $\mathrm{BHJ}$ is related to the difference between the HOMO of the donor and the LUMO of the electron acceptor.

We have presented, in the Table 1 , the orbital energies of the studied flavonoids, $\mathrm{E}_{\text {Hомо, }} \mathrm{E}_{\text {LUMO, }}$ $E_{\text {gap }}$ and the voltage theoretical values in open circuit $\mathrm{V}_{\text {oc }}(\mathrm{eV})$ Equation (2). Another parameter noted as $a_{i}$ is the difference between the energy levels of LUMO Mi compounds studied and the level of HOMO PCBMC60 energy equation (3).

As Table 1 shows, the HOMO and LUMO energies of the studied compounds are slightly different.
This shows that the nature of skeletons and substituents plays a key role in the electronic properties. In particular, the effect of the nature and position of the different substituents on the HOMO and LUMO energy level is clearly visible. The effect and the nature of the groups $(\mathrm{OH}$ and $\mathrm{OMe}$ ) attached to the aromatic cycle of the studied molecule on the values of calculated energies is clearly visible.

Thus, the $E_{\text {gap }}$ of the studied molecules differ slightly from $3.905 \mathrm{eV} 4.314 \mathrm{eV}$ according to this order:

$$
\begin{gathered}
M 9<M 8<M 2<M 3<M 1<M 6<M 7<M 4< \\
M 5<M 11<M 13<M 12<M 10
\end{gathered}
$$

Let us remember that the $\mathrm{E}_{\text {LUMO }}$ of donor must be greater than that of CB of PCBM C60 (12) "the values of a must be positive". We have noted that the $E_{\text {LUMO }}$ values of $\mathrm{Mi}$ are higher than that of PCBM. In fact, possibilities of electron transfer are possible. On the other hand, the heterojunction structure (BHJ stands for blend heterojunction) is a mixture of two organic semiconductors between two electrodes in which all the photogenerated 
excitons will be able to diffuse without recombining to a donor / acceptor interface and dissociate whatever the of the exciton creation site. This structure therefore makes it possible to exceed the constraint of the limitation of the thicknesses by the diffusion length of the exciton $(13,14)$.

The values obtained of $\mathrm{V}_{\text {oc }}$ are in the range 1.510 eV - $2.205 \mathrm{eV}$ (see Table 1). These results are sufficient to suggest these molecules for photovoltaic applications because the process of electron injection of the studied molecule to the PCBMC60 conduction band and the subsequent regeneration are feasible in an organic solar cell. Also, to effectively inject the electron into the PCBMC60 conduction band; the value of LUMO of the donor must be greater than that of PCBMC60, this is verified in Table 1 for the studied molecules. 
Kacimi et al. JOTCSA. 2018; 5(3): 1009-1020.

Table 1: Energy values of $E_{\text {LUMO }}(e V), E_{\text {HOMO }}(e V)$. $E_{\text {gap }}(e V)$, the circuit voltage $V_{\text {oc }}(e V)$ and a of the studied molecules.

\begin{tabular}{cccccc}
\hline Compounds & E $_{\text {номо }}(\mathbf{e V})$ & $\mathbf{E}_{\text {Lumo }}(\mathbf{e V})$ & $\mathbf{E}_{\text {gap }}(\mathbf{e V})$ & $\mathbf{V o c}(\mathbf{e V})$ & $\mathbf{a}(\mathbf{e V})$ \\
\hline M1 & -5.678 & -1.711 & 3.967 & 1.678 & 1.989 \\
M2 & -5.836 & -1.901 & 3.935 & 1.836 & 1.799 \\
M3 & -5.717 & -1.777 & 3.940 & 1.717 & 1.923 \\
M4 & -5.691 & -1.717 & 3.974 & 1.691 & 1.983 \\
M5 & -5.662 & -1.678 & 3.984 & 1.662 & 2.022 \\
M6 & -5.650 & -1.683 & 3.967 & 1.650 & 2.017 \\
M7 & -5.833 & -1.862 & 3.971 & 1.833 & 1.838 \\
M8 & -5.751 & -1.817 & 3.933 & 1.751 & 1.883 \\
M9 & -5.510 & -1.605 & 3.905 & 1.510 & 2.095 \\
M10 & -6.205 & -1.891 & 4.314 & 2.205 & 1.809 \\
M11 & -6.036 & -1.970 & 4.065 & 2.036 & 1.730 \\
M12 & -6.023 & -1.818 & 4.204 & 2.023 & 1.882 \\
M13 & -5.978 & -1.776 & 4.202 & 1.978 & 1.924 \\
PCBM C60 & -6.100 & -3.700 & & & \\
\hline
\end{tabular}

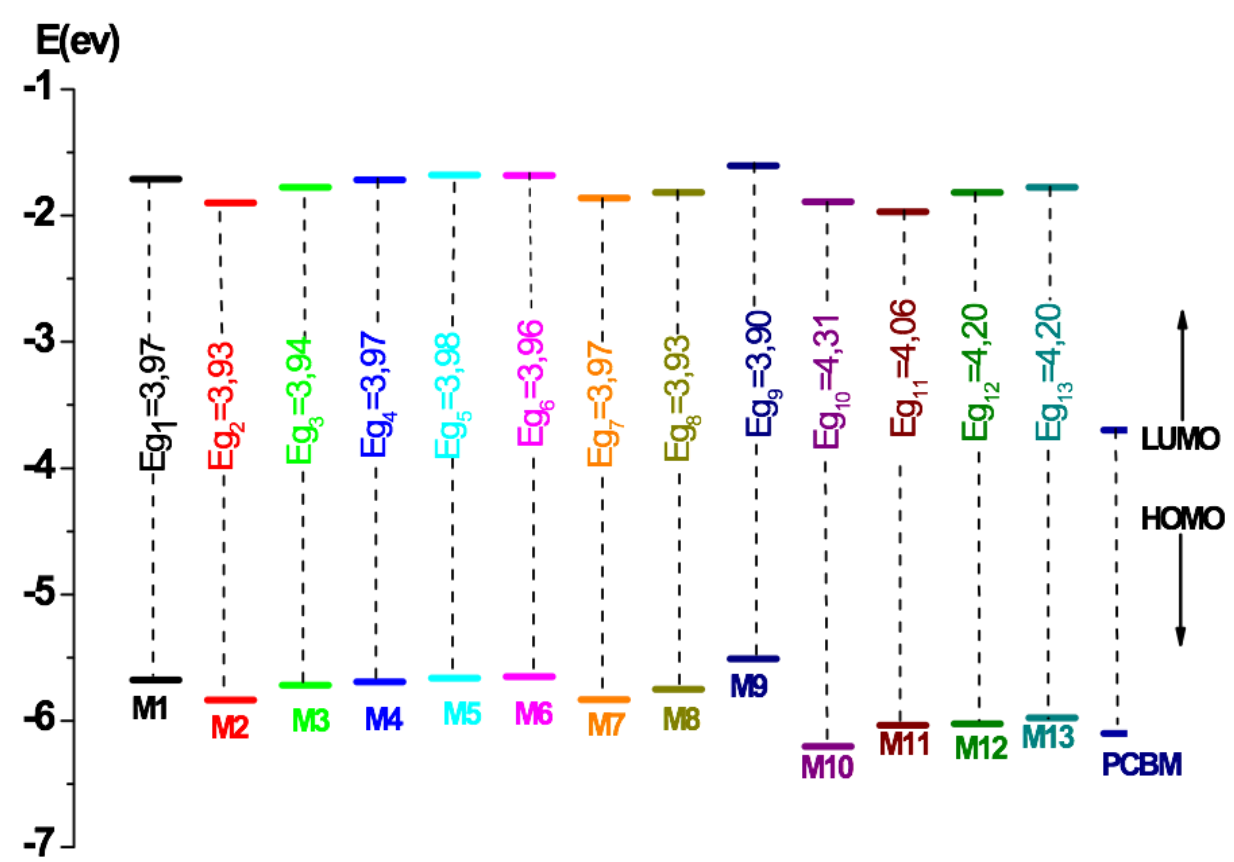

Figure 3: Sketch of the calculated energy of the HOMO. LUMO levels of studied molecules and PCBM.

In order to provide information regarding the excitation properties, one must examine the order and organization of the lobes in the HOMO and virtual LUMO occupied orbitals (12). So we have presented in Figure 4, the obtained lobes of the occupied orbital HOMO and the virtual LUMO from each optimized structure.

The results of Figure 4 show that the HOMO has an anti-binding character while the LUMO of all 
the compounds generally has a binding character between the subunits(13).

HOMO
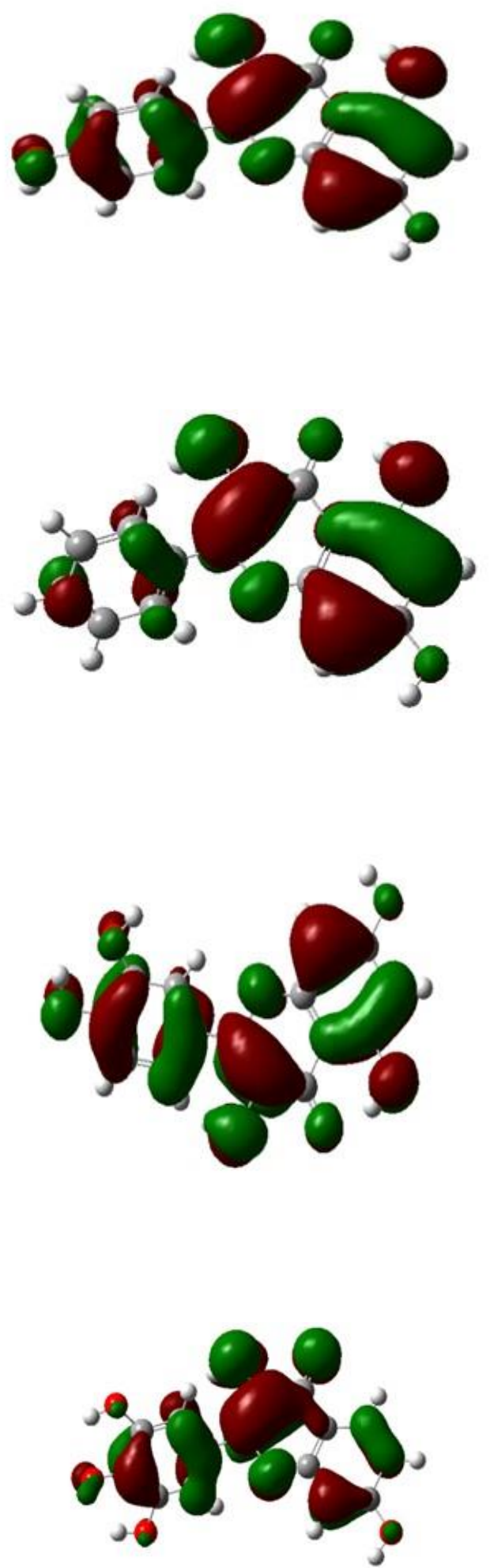

M1

M2

LUMO
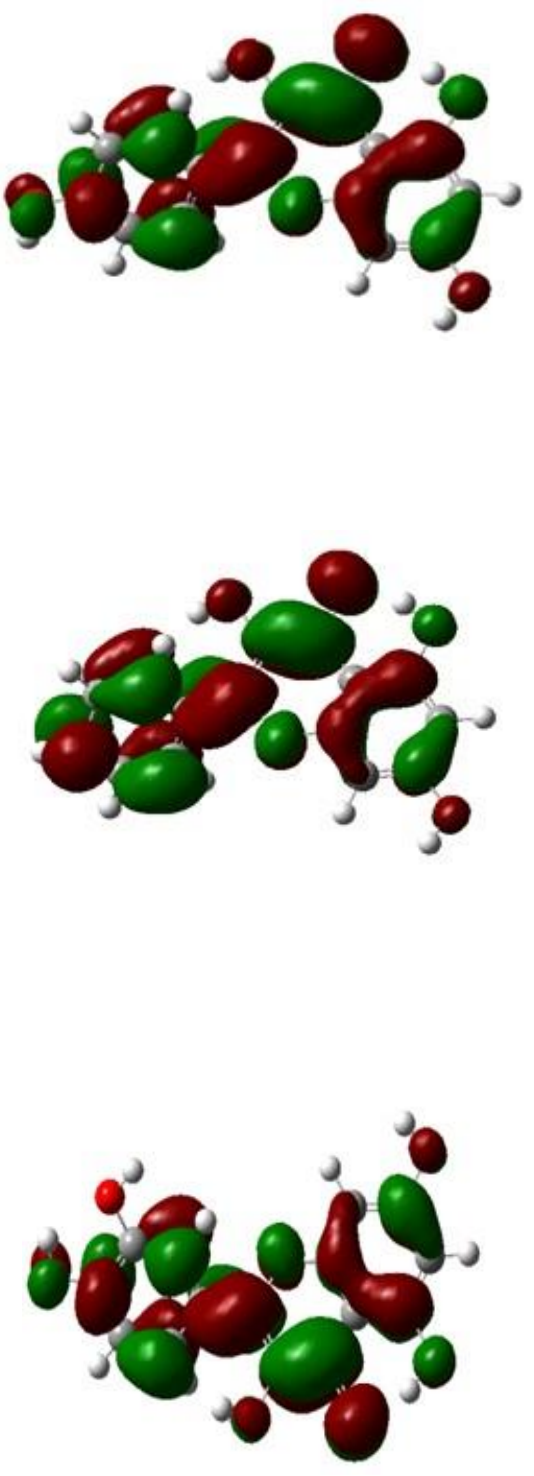

M3

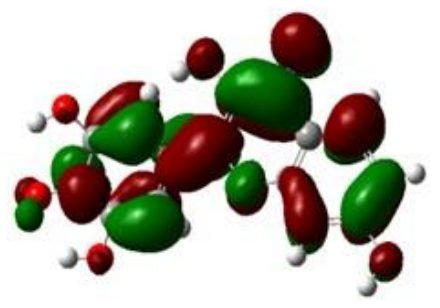



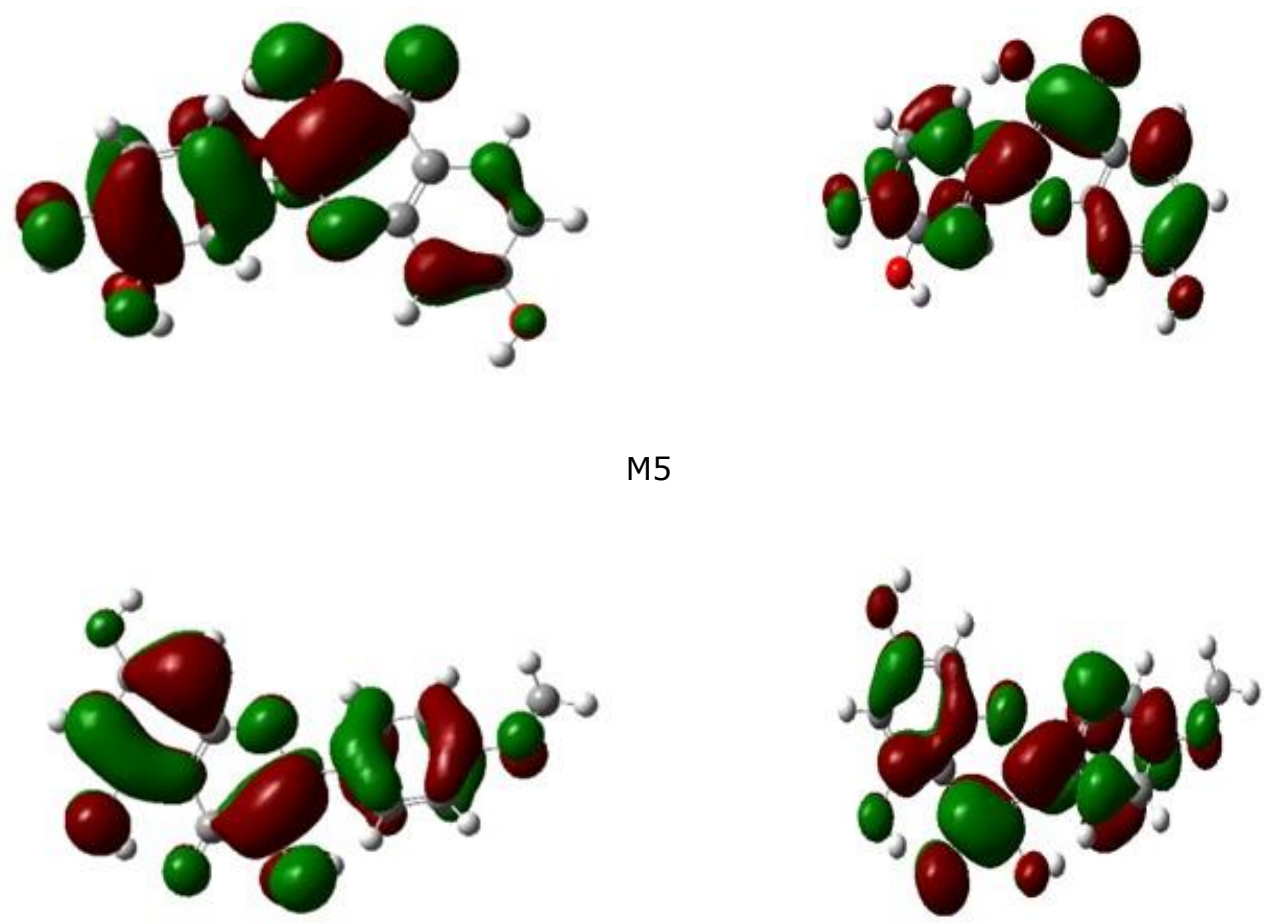

M6
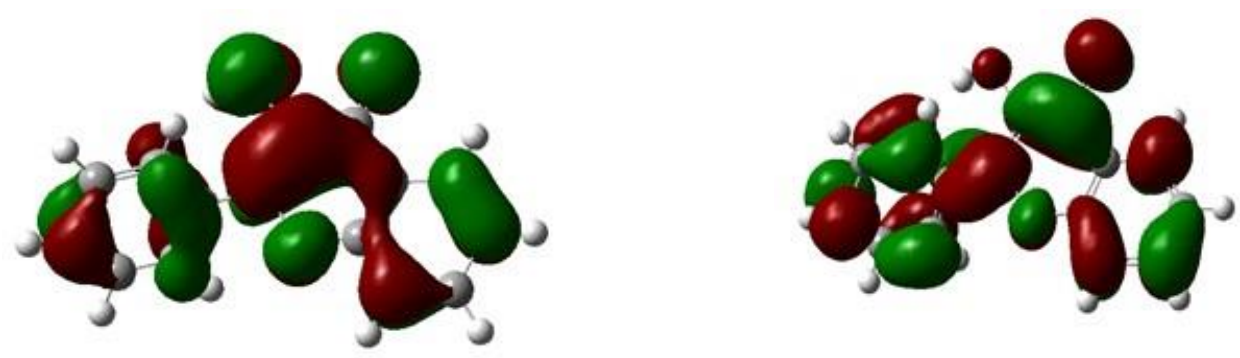

M7
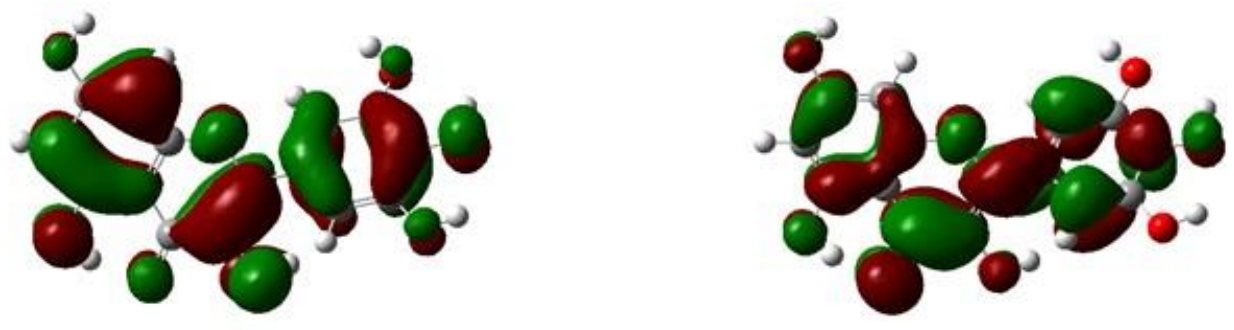

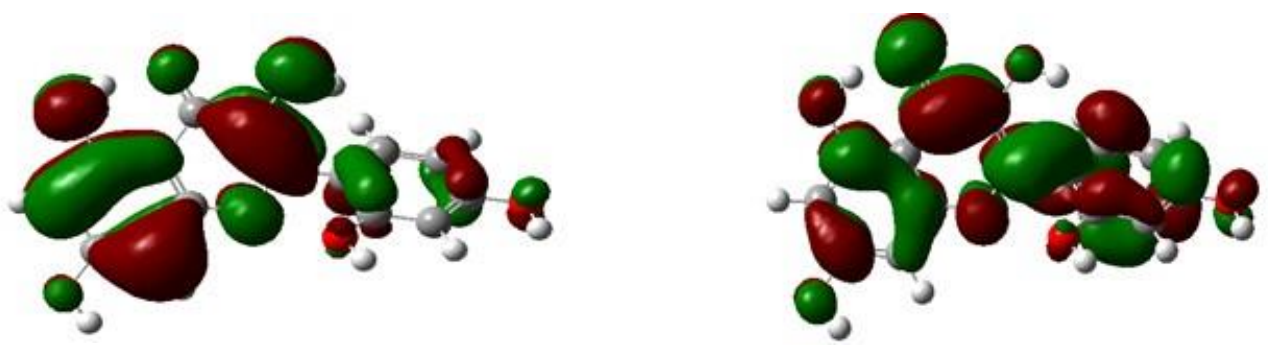

M9
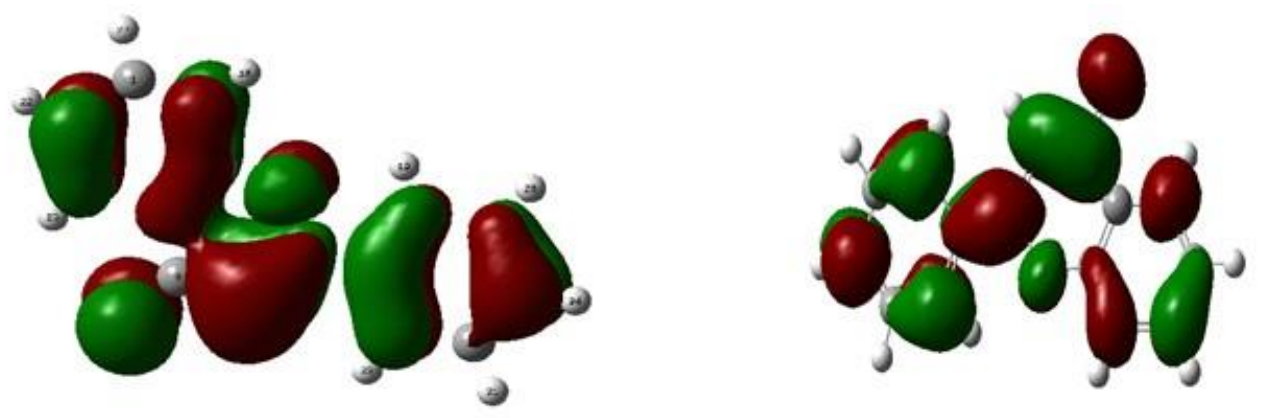

M10
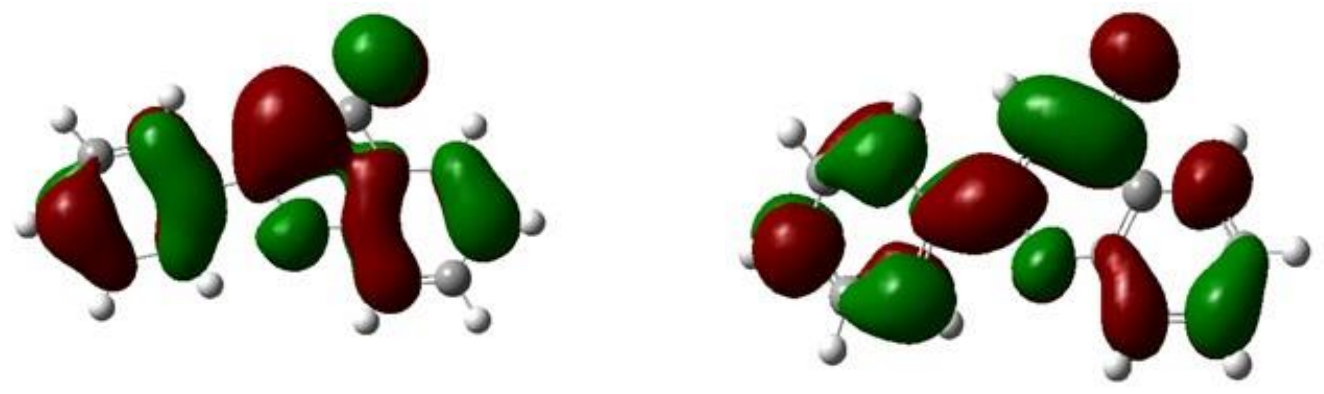

M11
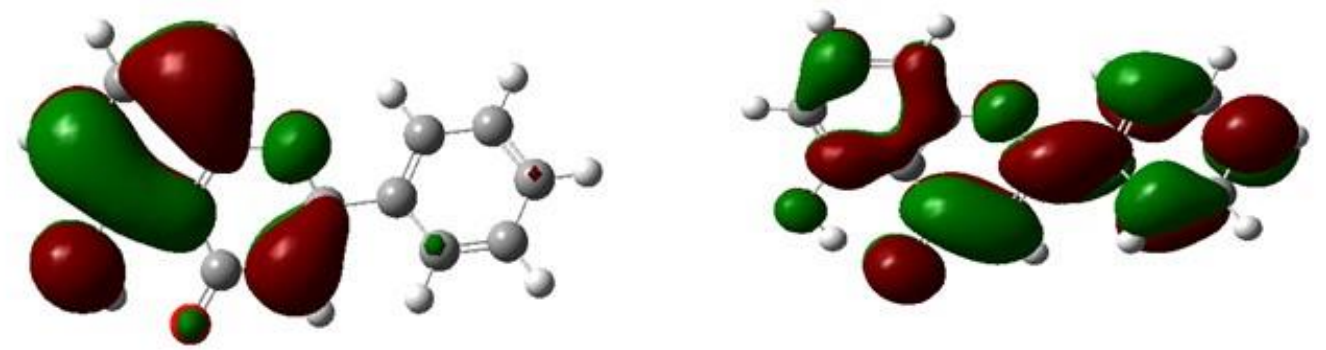

M12 

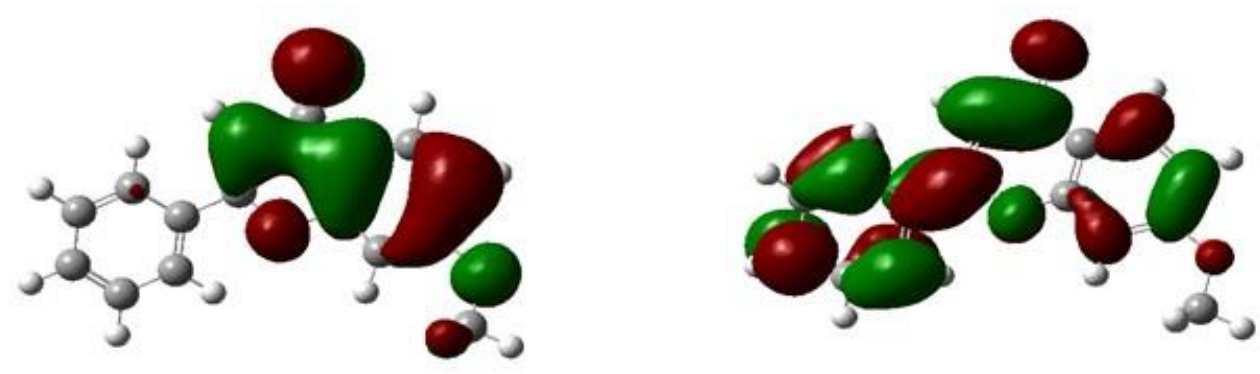

M13

Figure 4: The contour plots of HOMO and LUMO orbitals of the studied compounds obtained by B3LYP/6$31(d, p)$ level.

It is important to mention that a good photovoltaic material must have as wide spectrum of absorption as possible and absorb in the visible range of the electromagnetic spectrum(14). Because the absorption properties are a key factor for suggesting photovoltaic applications, the UV-visible spectra of the compounds $(\mathrm{Mi})$ were determined by using TDDFT method. So, we have presented in Table 2, the absorption maximum detailed calculation wavelength $\left(\lambda_{\max }\right)$, the oscillator strength (OS), the transition energy ( $\left.E_{\mathrm{ex}}\right)$ and the main molecular orbital (MO) involved in the transition are listed in Table 2. We found that all optical absorption corresponds to transitions from HOMO to LUMO +1. Moreover compared to M13, the maximum absorption peak shows a bathochromic shift of 398-522 nm.

Let us remember that the first excitation corresponds almost exclusively to the passage of an electron from the HOMO level to the LUMO level(15). The absorption wavelengths resulting from the electronic transition SO $\rightarrow$ S1 increases progressively as the conjugated chain increases. This is reasonable since the transition HOMO $\rightarrow$ LUMO is predominant in the electronic transition $\mathrm{SO} \rightarrow \mathrm{S} 1$; that the results are a decrease in LUMO and an increase in HOMO energy.

Table 2: Absorption spectra obtained by TD-DFT method for $M(i=1$ to 13 ).

\begin{tabular}{|c|c|c|c|c|c|}
\hline Compounds & $\lambda_{\max }(\mathbf{n m})$ & $E_{e x}(e V)$ & O.S (eV) & \multicolumn{2}{|c|}{ MO/character $(\%)$} \\
\hline M1 & 352.31 & 3.52 & 0.19 & HOMO & $\longrightarrow$ LUMO+1 $(83 \%)$ \\
\hline M2 & 359.22 & 3.45 & 0.13 & HOMO & $\longrightarrow$ LUMO $+1(87 \%)$ \\
\hline M3 & 353.58 & 3.50 & 0.22 & HOMO & $\longrightarrow$ LUMO $+1(81 \%)$ \\
\hline M4 & 323.87 & 3.83 & 0.27 & HOMO & $\longrightarrow$ LUMO+1 $(70 \%)$ \\
\hline M5 & 328.22 & 3.77 & 0.36 & HOMO & $\longrightarrow$ LUMO $+1(83 \%)$ \\
\hline M6 & 352.61 & 3.51 & 0.22 & HOMO & $\longrightarrow$ LUMO $+1(83 \%)$ \\
\hline M7 & 354.36 & 3.50 & 0.22 & HOMO & $\longrightarrow$ LUMO $+1(87 \%)$ \\
\hline M8 & 354.36 & 3.50 & 0.22 & HOMO & $\longrightarrow$ LUMO $+1(81 \%)$ \\
\hline M9 & 342.16 & 3.62 & 0.15 & HOMO & $\longrightarrow$ LUMO $+1(86 \%)$ \\
\hline M10 & 371.95 & 3.33 & 0.00 & HOMO & $\longrightarrow$ LUMO $+1(89 \%)$ \\
\hline M11 & 361.79 & 3.42 & 0.04 & HOMO & $\longrightarrow$ LUMO $+1(93 \%)$ \\
\hline M12 & 353.86 & 4.16 & 0.20 & HOMO & $\longrightarrow$ LUMO $+1(66 \%)$ \\
\hline M13 & 301.88 & 4.10 & 0.20 & HOMO & $\longrightarrow$ LUMO+1 $(58 \%)$ \\
\hline
\end{tabular}

Figure 5 shows the calculated optical absorption spectra. We note that the values of $\left(\lambda_{\max }\right)$ of thirteen studied compounds are in the order of $\mathrm{M} 10>\mathrm{M} 11>\mathrm{M} 2>\mathrm{M} 8>\mathrm{M} 7>\mathrm{M} 12>\mathrm{M} 3>\mathrm{M} 6>$ 
M1 > M9 > M5 > M4 > M13 (see Table 2). The strongest absorption in UV-visible $\left(\lambda_{\max }>300\right.$ $\mathrm{nm}$ ) corresponds to electronic transition HOMOLUMO+1 of all compounds. The increase of a bathochromic shift of thirteen compounds is attributed to increase of the conjugated system of these compounds when going from M13-M1 which also can be seen respectively in $M 13$ (301.88 nm), M4 (323.87 nm), M5 (328.22 nm), M9 (342.16 nm), M1 (352.31 nm), M6 (352.61
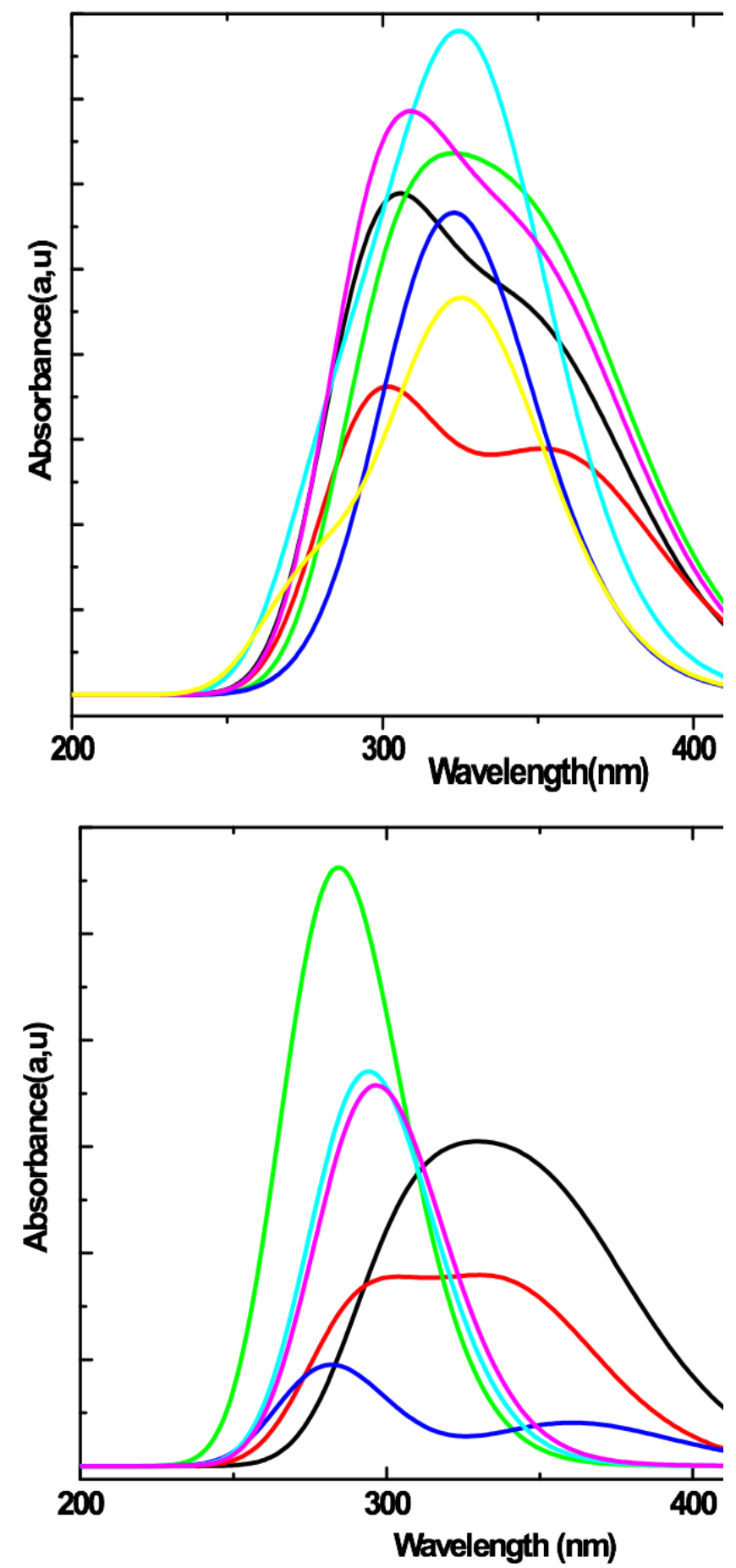

Figure 5: Simulated UV-visible optical absorption spectra of studied compounds obtained by using TD-DFT/B3LYP/6-31G(d,p). $\mathrm{nm})$, M3 (353.58 nm), M12 (353.86 nm), M7 $(354.36 \mathrm{~nm}), M 8(354.36 \mathrm{~nm}), M 2(359.22 \mathrm{~nm})$, M11 (361.79 nm) and M10 (371.95 nm). This effect comes from the fact that the studied compounds have different structures and different aromaticity, and the effects of the nature and the position of the substitution in the aromatic cycles. These interesting remarks are already confirmed by the study of the electronic properties in the previous paragraph. 


\section{CONCLUSION}

In this work, we have analyzed the quantum and electronic properties of various flavonoids and derivatives using the DFT / B3LYP6-31G (d,p) method. This allowed, first, the prediction of the geometric, electronic and absorption properties; then, the calculation of the photovoltaic properties by empirical formulas and finally, the possibility of proposing them for optoelectronic applications. The results show that:

The calculated $E_{\text {gap }}$ vary from 3.905 to 4.314 (eV);

The molecule M9 has a low band gap compared to other compounds;

$\checkmark$ The calculated $V_{\text {oc }}$ values vary from 2.205 $\mathrm{eV}$ to $1.510 \mathrm{eV}$;

$\checkmark$ Absorption spectra were obtained at TDB3LYP / 6-31G (d,p) levels, the absorption maxima obtained are in the range of $301.88-371.95 \mathrm{~nm}$;

Finally, the results of the quantum chemical calculations used in this study show that all the studied flavonoids could be used as donor molecules with the PCBM receptor in BHJ type organic solar cells. Thanks to advanced computing tools such as GAUSSIAN 9.0, quantum chemistry can be used for the prediction of physicochemical properties, in particular electronic properties. This will guide the experimental chemists to design diversified structures precursors of new materials for optoelectronic applications.

\section{REFERENCES}

1. Buer CS, Imin $N$, Djordjevic MA. Flavonoids: new roles for old molecules. Journal of integrative plant biology. 2010;52(1):98-111.

2. Rice-Evans CA, Miller NJ, Paganga G. Structure-antioxidant activity relationships of flavonoids and phenolic acids. Free radical biology and medicine. 1996;20(7):933-56.

3. Kong J-M, Chia L-S, Goh N-K, Chia T-F, Brouillard R. Analysis and biological activities of anthocyanins. Phytochemistry. 2003;64(5):92333.

4. Farkas $\mathrm{O}$, Jakus J, Héberger $\mathrm{K}$. Quantitative structure-antioxidant activity relationships of flavonoid compounds. Molecules. 2004;9(12):1079-88.

5. Marcussi DG. Desenvolvimento e avaliação das atividades antioxidante e despigmentante in vitro de emulsões múltiplas a/o/a contendo dipalmitato kójico. 2012.

6. Cao W, Hu S-S, Li X-Y, Pang X-Q, Cao J, $\mathrm{Ye} \mathrm{L}-\mathrm{H}$, et al. Highly sensitive analysis of flavonoids by zwitterionic microemulsion electrokinetic chromatography coupled with lightemitting diode-induced fluorescence detection.
Journal of Chromatography A. 2014;1358:27784.

7. Li C, Ma C, Li D, Liu Y. Excited state intramolecular proton transfer (ESIPT) of 6amino-2-(2'-hydroxyphenyl) benzoxazole in dichloromethane and methanol: a TD-DFT quantum chemical study. Journal of Luminescence. 2016;172:29-33.

8. Kaya S, Guo L, Kaya C, Tüzün B, Obot I, Touir R, et al. Quantum chemical and molecular dynamic simulation studies for the prediction of inhibition efficiencies of some piperidine derivatives on the corrosion of iron. Journal of the Taiwan Institute of Chemical Engineers. 2016;65:522-9.

9. Goswami S, Aich K, Das S, Pakhira B, Ghoshal K, Quah CK, et al. A Triphenyl AmineBased Solvatofluorochromic Dye for the Selective and Ratiometric Sensing of $\mathrm{OCl}-$ in Human Blood Cells. Chemistry-An Asian Journal. 2015;10(3):694-700.

10. Sabirov DS, Terentyev AO, Bulgakov RG. Counting the Isomers and Estimation of Anisotropy of Polarizability of the Selected C60 and C70 Bisadducts Promising for Organic Solar Cells. The Journal of Physical Chemistry A. 2015;119(43):10697-705.

11. Bourass $M$, Benjelloun AT, Benzakour $M$, Mcharfi M, Hamidi M, Bouzzine SM, et al. DFT and TD-DFT calculation of new thienopyrazine-based small molecules for organic solar cells. Chemistry Central Journal. 2016;10(1):67.

12. Wazzan N, El-Shishtawy RM, Irfan A. DFT and TD-DFT calculations of the electronic structures and photophysical properties of newly designed pyrene-core arylamine derivatives as hole-transporting materials for perovskite solar cells. Theoretical Chemistry Accounts. 2018;137(1):9.

13. Jia C, Zhang J, Bai J, Zhang L, Wan Z, Yao $X$. Synthesis, physical properties and selfassembly of conjugated donor-acceptor system based on tetrathiafulvalene and functionalized with binding sites. Dyes and Pigments. 2012;94(3):403-9.

14. Grinberg I, West DV, Torres M, Gou G, Stein DM, Wu L, et al. Perovskite oxides for visible-light-absorbing ferroelectric and photovoltaic materials. Nature. 2013;503(7477):509.

15. Wojtkiewicz J, Iwan A, Pilch $M$, Boharewicz B, Wójcik K, Tazbir I, et al. Towards designing polymers for photovoltaic applications: A DFT and experimental study of polyazomethines with various chemical structures. Spectrochimica Acta Part A: Molecular and Biomolecular Spectroscopy. 2017;181:20817. 